\title{
Prediction of development length from free-end slip in pretensioned concrete members
}

\author{
Canh N. Dang \\ Department for Management of Science and Technology Development, \\ Ton Duc Thang University, Ho Chi Minh City, Vietnam; Faculty of Civil \\ Engineering, Ton Duc Thang University, Ho Chi Minh City, Vietnam \\ (canhdang@tdt.edu.vn) \\ Royce W. Floyd \\ Assistant professor, School of Civil Engineering and \\ Environmental Science at the University of Oklahoma in Norman, \\ Oklahoma, USA
}

\author{
W. Micah Hale \\ Professor and head, Department of Civil Engineering at the University of \\ Arkansas in Fayetteville, Arkansas, USA \\ José R. Martí-Vargas \\ Professor, School of Civil Engineering (Department of Construction \\ Engineering and Civil Engineering Projects) and Researcher, ICITECH \\ (Institute of Concrete Science and Technology) at the Universitat Politècnica \\ de València, Valencia, Spain (corresponding author: jrmarti@cst.upv.es) \\ (Orcid:0000-0003-1665-2348)
}

Development length of prestressing strands is a significant parameter in the design of pretensioned concrete members. The adequacy of the code equations used to predict the development length needs to be verified when a new material or design parameter is introduced for precast, prestressed concrete applications. This study develops a simple and reliable technique to quantify the development length based on the premise of the slip theory, which proposes the free-end slip (FES) as an indicator of the development length. Twenty-five pretensioned concrete beams were cast with $15 \mathrm{~mm}$ diameter strands. FES was measured at both beam ends at prestress transfer. Development length was determined by performing bending tests at different embedment lengths. The experimental results were synthesised to revise the slip theory. The applicability of the revised-slip theory was validated by collected experimental data of pretensioned concrete members using various types of concrete, strand diameters and release techniques.

\section{Notation}

$d_{b} \quad$ nominal strand diameter $(\mathrm{mm})$

$E_{\mathrm{p}} \quad$ modulus of elasticity of prestressing strands (MPa)

$f_{\mathrm{c}}^{\prime} \quad$ concrete's compressive strength at $28 \mathrm{~d}(\mathrm{MPa})$

$f_{\mathrm{ci}}^{\prime} \quad$ concrete's compressive strength at $1 \mathrm{~d}(\mathrm{MPa})$

$f_{\mathrm{pe}} \quad$ strand stress after allowance for all prestress losses

$f_{\mathrm{pi}} \quad$ strand stress just before release (MPa)

$f_{\mathrm{ps}} \quad$ average stress in prestressing steel at the time for which the nominal flexural capacity of a member is required (MPa)

$f_{\mathrm{pt}} \quad$ strand stress prior to prestress transfer (MPa)

$f_{\mathrm{pu}} \quad$ ultimate strength of prestressing strand (MPa)

$L_{\mathrm{d}} \quad$ development length $(\mathrm{mm})$

$L_{\mathrm{e}} \quad$ embedment length (mm)

$L_{\mathrm{t}} \quad$ transfer length $(\mathrm{mm})$

$M_{\max }$ maximum measured moment $(\mathrm{kN} \mathrm{m})$

$M_{\mathrm{n}} \quad$ nominal flexural resistance $(\mathrm{kN} \mathrm{m})$

$T_{500}$ time when concrete has flowed to a diameter of $500 \mathrm{~mm}(\mathrm{~s})$

$\alpha \quad$ bond stress distribution coefficient (dimensionless)

$\Delta_{\mathrm{ES}} \quad$ elastic shortening of the free portion of prestressing strands $(\mathrm{mm})$

$\Delta_{\mathrm{f}} \quad$ final reading of end-slip measurement (mm)

$\Delta_{\mathrm{i}} \quad$ initial reading of end-slip measurement (mm)

$\delta \quad$ free-end slip (FES) (mm)

$\delta_{\text {all }} \quad$ threshold of free-end slip (mm)

\section{Introduction}

In the design of pretensioned concrete girders, the transfer length and development length of prestressing strands are significant parameters for examination of allowable stresses at release and the calculation of shear strength and flexural resistance (Mitchell et al., 1993; Russell and Burns, 1993). Transfer length is the required length for the prestressing strands to transfer the effective prestress $\left(f_{\mathrm{pe}}\right)$ to the concrete. Development length is the required length to develop the strand stress $\left(f_{\mathrm{ps}}\right)$ at the nominal flexural resistance of the member. These lengths can be predicted by using equations such as Equation 1 (ACI, 2014). In this equation, the first term represents the transfer length. The strand stress is assumed to be linearly increased from zero to $f_{\mathrm{pe}}$ in the transfer zone, and from $f_{\mathrm{pe}}$ to $f_{\mathrm{ps}}$ in the flexural-bond zone.

1. $L_{\mathrm{d}}=\frac{1}{20 \cdot 7} f_{\mathrm{pe}} d_{b}+\frac{1}{6 \cdot 9}\left(f_{\mathrm{ps}}-f_{\mathrm{pe}}\right) d_{b}$

Equation 1 was based on the bond between $13 \mathrm{~mm}$ diameter strands and vibrated, normal-weight concrete (Hanson and Kaar, 1959; Tabatabai and Dickson, 1993). Because of factors affecting bond, Equation 1 needs to be validated when a new material, either concrete or prestressing strands, or a new design parameter is introduced (Dang, 2015). These factors have been analysed by several researchers (Lees and Burgoyne, 1999; Martí-Vargas et al., 2013a, 2013b; Mayfield et al., 1970). In the current practice, a number of new types of concrete and prestressing strand are used for precast, prestressed concrete applications. Self-consolidating concrete (SCC) and lightweight SCC (Bymaster et al., 2015) and increased strand diameter (Dang et al., 2016b, 2016c; Maguire et al., 2013; 
Morcous et al., 2014; Song et al., 2013) are recent developments in the concrete industry. However, when compared with a normal-weight, non-SCC mixture, a greater amount of paste in SCC or a lower stiffness of aggregates in lightweight SCC can weaken the strand-concrete bond (Burgueño and Haq, 2007; Floyd et al., 2015). Also, increase in strand diameter or reduction in strand spacing affects the transfer and development lengths (Dang, 2015). Therefore, a number of tests need to be conducted to validate the adequacy of the current transfer- and development-length equations.

The transfer length can be quantified by measuring concrete surface strains, strand strains, strand stress or FES (Martí-Vargas et al., 2006; Russell and Burns, 1993). The first technique is reliable but time consuming (Dang et al., 2016d), while the second technique possibly causes unreliable results (Russell and Burns, 1997) and the third technique requires series of specimens with different embedment lengths (Martí-Vargas et al., 2006). As the slip at the free end of a pretensioned concrete member at release accounts for the whole of slips along the transfer length (Abdelatif et al., 2015; Martí-Vargas et al., 2014), the use of FES can provide a prediction of the transfer length, and it is practical for implementation at precast plants because of its simplicity (Park et al., 2012; Rose and Russell, 1997). For the development length determination, bending tests are normally used, which are costly as several full-scale pretensioned concrete girders have to be tested, and adequate facilities are required, which is not practical at precast plants.

Therefore, there is a need to develop a simple and reliable technique to quantify the development length. In this study, the researchers develop criteria for prediction of development length using the measured FES at prestress transfer. The developed technique can support the precast manufacturers in quantifying possible deviations in the fabrication and construction of their products quickly and routinely.

\section{Research significance}

The slip theory can be used to predict the development length of prestressing strands from the measured FES for pretensioned concrete members. In the literature, the applicability of the slip theory was validated for normal-weight, vibrated concrete. Regardless of the benefits of self-compacting concrete in the construction of long-span bridges, its use possibly results in greater FES, transfer length and development length due to the weakness of the concrete adjacent to the strands. Therefore, the applicability of the slip theory is questionable and needs to be further investigated. In this study, the researchers measure the FESs and development lengths for 25 pretensioned concrete beams cast with six SCC and lightweight SCC mixtures. The experimental results are synthesised to propose a new technique for predicting the development length.

\section{Literature review}

The FES is an indicator of the strand-to-concrete bond in the transfer zone, and it is related with the transfer length based on Equation 2 (Guyon, 1953). The accuracy of this equation depends on the empirical coefficient $\alpha$ that represents the bond distribution along the transfer zone. A coefficient of 2.0 can be adopted to predict the transfer length assuming linear strand stress (uniform bond) (Oh and Kim, 2000; Rose and Russell, 1997).

2. $L_{\mathrm{t}}=\alpha \delta \frac{E_{\mathrm{p}}}{f_{\mathrm{pt}}}$

Anderson and Anderson (1976) proposed a correlation between the ability to achieve the transfer bond and the flexural resistance in pretensioned concrete members by using the excessive FES as a predictor for the occurrence of the bond failure. The excessive FES (and transfer length) can increase the development length to a level greater than the predicted value using Equation 1. Accordingly, the pretensioned concrete member tends to show a premature bond failure when the nominal flexural strength (Mitchell et al., 1993) or the shear capacity (Elliott, 2014; Elliott and Martí-Vargas, 2015) is required at the predicted location. A threshold for the FES as shown in Equation 3, which was obtained by combining the first term of Equations 1 and 2, was used by Anderson and Anderson (1976) as a quality-assurance criterion for hollowcore slabs.

3. $\delta_{\text {all }}=0.024 \frac{f_{\mathrm{pi}} f_{\mathrm{pt}}}{E_{\mathrm{p}}} d_{b}$

Brooks et al. (1988) further examined the concept proposed by Anderson and Anderson (1976) and found that the slabs with FES $<\delta_{\text {all }}$ achieved the nominal flexural strength when tested at the predicted development length according to Equation 1. This has been referred to as the slip theory in the literature, which was simplified and validated by Logan (1997) who proposed a $\delta_{\text {all }}$ of $2.3 \mathrm{~mm}$ for $13 \mathrm{~mm}$ diameter strands in pretensioned concrete beams.

Petrou et al. (2000) and Wan et al. (2002) also recommended using FES as an indicator to quantify the transfer length and the ultimate strength of prestressed piles, respectively. In this way, the adoption of a $\delta_{\text {all }}$ allows the precast, prestressed concrete manufacturers to examine their products routinely and also when a new type of concrete or prestressing strand is required for production.

\section{Experimental investigation}

The experimental programme consisted of five tasks: (a) development of concrete mixtures, $(b)$ examination of strand surface conditions; (c) fabrication of 25 pretensioned concrete beams, $(d)$ measurement of FES at prestress transfer and 
Table 1. Concrete mixture proportions

$\begin{array}{lcccccc}\text { Material } & \text { NSC } & \text { NSS } & \text { NSL } & \text { HSC } & \text { HSS } & \text { HSL } \\ \text { Cement type l: } \mathrm{kg} / \mathrm{m}^{3} & 489 \cdot 6 & 504 \cdot 4 & 459 \cdot 9 & 479 \cdot 5^{\mathrm{a}} & 493 \cdot 8^{\mathrm{a}} & 489 \cdot 6 \\ \text { Fly ash: } \mathrm{kg} / \mathrm{m}^{3} & 0 \cdot 0 & 0 \cdot 0 & 0 \cdot 0 & 84 \cdot 3 & 87 \cdot 2 & 0 \cdot 0 \\ \text { Coarse aggregate: } \mathrm{kg} / \mathrm{m}^{3} & 385 \cdot 2 & 443 \cdot 9 & 835 \cdot 6 & 385 \cdot 2 & 417 \cdot 2 & 826 \cdot 1 \\ \text { Fine aggregate: } \mathrm{kg} / \mathrm{m}^{3} & 835 \cdot 0 & 852 \cdot 8 & 878 \cdot 9 & 737 \cdot 1 & 753 \cdot 7 & 832 \cdot 6 \\ \text { Water: } \mathrm{kg} / \mathrm{m}^{3} & 195 \cdot 2 & 176 \cdot 9 & 184 \cdot 0 & 197 \cdot 6 & 197 \cdot 6 & 195 \cdot 8 \\ \text { Water/cement ratio } & 0 \cdot 40 & 0 \cdot 35 & 0 \cdot 40 & 0 \cdot 35 & 0 \cdot 34 & 0 \cdot 40 \\ \text { Slump flow: mm } & 640-710 & 660-750 & 480-690 & 650-740 & 660-770 & 660-710 \\ f_{\text {c: }}^{\prime}: \text { MPa } & 26 \cdot 2-38 \cdot 6 & 25 \cdot 5-31 \cdot 0 & 27 \cdot 6-38 \cdot 6 & 39 \cdot 3-44 \cdot 8 & 32 \cdot 6-47 \cdot 8 & 47 \cdot 1-48 \cdot 4 \\ f_{c}^{\prime}: \text { MPa } & 33 \cdot 8-49 \cdot 6 & 40 \cdot 0-49 \cdot 0 & 46 \cdot 2-55 \cdot 2 & 45 \cdot 9-54 \cdot 6 & 40 \cdot 3-55 \cdot 6 & 61 \cdot 4-74 \cdot 4\end{array}$

andicates cement type III

(e) determination of development length after the beams reached $28 \mathrm{~d}$ of age.

\subsection{Concrete mixtures}

The mix proportions are shown in Table 1. Six concrete mixtures were developed. Limestone, clay or shale was used as the coarse aggregate. For designation purposes, the first two letters represent the strength level (NS for normal-strength concrete and HS for high-strength concrete), and the third letter represents the type of coarse aggregate ( $\mathrm{L}$ for limestone, $\mathrm{C}$ for clay and S for shale). NSL and HSL are the two normalweight SCC mixtures. The four lightweight SCC mixtures were NSC, NSS, HSC and HSS. Each concrete mixture was used to cast four pretensioned concrete beams, excluding the NSS, which was used to cast five beams.

ASTM C127 (ASTM, 2015) was used to determine the absorption capacity of the aggregates to make an appropriate adjustment for the water content. The filling ability, passing ability and segregation resistance of the six concrete mixtures were examined using a slump flow test and $T_{500}$ (ASTM C1611 (ASTM, 2014a)), J-Ring test (ASTM C1621 (ASTM, 2014b)) and Visual Stability Index (ASTM C1611 (ASTM, 2014a)), respectively. External vibration was partially used to assist concrete consolidation for the mixtures having a slump flow less than $600 \mathrm{~mm}$. The remaining parameters showed a good agreement with the recommended thresholds presented in Table 10 of the National Cooperative Highway Research Program (NCHRP) Report 628 (Khayat and Mitchell, 2009).

The compressive strengths at prestress transfer varied from 25.5 to $38.6 \mathrm{MPa}$ for NSC, and from 32.6 to $48.4 \mathrm{MPa}$ for HSC. At $28 \mathrm{~d}$ of age, the compressive strengths varied from 33.8 to $55.2 \mathrm{MPa}$ and from 40.3 to $74.4 \mathrm{MPa}$ for NSC and HSC, respectively. The compressive strengths of the lightweight concrete at prestress transfer were similar to those of the normal-weight concrete. However, the 28-d strengths of the normal-weight concrete were slightly greater than those of the lightweight concrete. This deviation is due to the concrete strength at the early age being mainly contributed by the mortar stiffness, whereas the strength at later ages is contributed by the mortar and aggregate stiffness.

\subsection{Examination of strand surface conditions}

ASTM A1081 (ASTM, 2012) was used to evaluate strand surface conditions. Six strand specimens were cut from a $915 \mathrm{~m}$ reel of $15 \mathrm{~mm}$ diameter strand. The mortar's compressive strength at the time the tests were conducted was $36 \mathrm{MPa}$. The test was conducted using an MTS machine. The tensile force at the loaded end and the strand movement at the free end were monitored using a data acquisition system. For a strand movement of $2.5 \mathrm{~mm}$, the average tensile force of the $15 \mathrm{~mm}$ diameter strands used in this study was $85.3 \mathrm{kN}$ with a standard deviation of $9 \cdot 4 \mathrm{kN}$ (as established in Dang et al. $(2014,2015)$ ).

\subsection{Beam fabrication}

The pretensioned concrete beams were cast at the Engineering Research Center at the University of Arkansas. Two beams were simultaneously cast on a $15 \mathrm{~m}$ prestressing bed. The beam had a rectangular cross-section of $165 \times 305 \mathrm{~mm}$ and a length of $5500 \mathrm{~mm}$. Each beam consisted of two $15 \mathrm{~mm}$, Grade 1860, prestressing strands that were placed at a distance of $255 \mathrm{~mm}$ from the top fibre of the beam. These strands were anchored at the dead end of the prestressing bed using chucks, and tensioned to $1396 \mathrm{MPa}$ at the live end using a hydraulic actuator. Two $19 \mathrm{~mm}$ reinforcing bars were placed at a distance of $50 \mathrm{~mm}$ from the top fibre of the beam to control the anticipated cracking at prestress transfer. The shear reinforcement consisted of $6.4 \mathrm{~mm}$ smooth bars placed at a $150 \mathrm{~mm}$ spacing along the entire beam length.

Six cylinders (100 by $200 \mathrm{~mm}$ ) were cast and cured adjacent to the beams until tested. The concrete was cured in the wooden forms for $20 \mathrm{~h}$ with a plastic sheet covering the top of the beams. Three cylinders were tested to evaluate the concrete's compressive strength prior to prestress transfer. The prestressing strands were gradually detensioned $24 \mathrm{~h}$ after casting the concrete. The beams were stored in an outdoor yard of the Engineering Research Center, and no special curing technique was applied. The other three cylinders were tested at $28 \mathrm{~d}$ of age. 


\subsection{Measurement of FES}

The procedure used to measure the FES consisted of four steps:

(1) A metal clamp with a micrometer was attached to each prestressing strand near the beam end. A small plate of mica was attached to the concrete surface at the end to create a flat surface to improve the accuracy of the readings.

(2) An initial reading $\left(\Delta_{\mathrm{i}}\right)$ was taken for each prestressing strand.

(3) The prestressing strands were detensioned by releasing the pressure in the hydraulic system (Figure 1) and cut.

(4) A final reading $\left(\Delta_{\mathrm{f}}\right)$ was taken for each prestressing strand. Equations 4 and 5 show the calculation of the FES and the elastic shortening, respectively. For each beam, the measured FESs of the two prestressing strands were similar, and the average FES for a specific beam end was reported assuming $E_{\mathrm{p}}=196 \cdot 5 \mathrm{GPa}$.

4. $\delta=\Delta_{\mathrm{f}}-\Delta_{\mathrm{i}}-\Delta_{\mathrm{ES}}$

5. $\Delta_{\mathrm{ES}}=\frac{f_{\mathrm{pt}}}{E_{\mathrm{p}}} \Delta_{\mathrm{i}}$

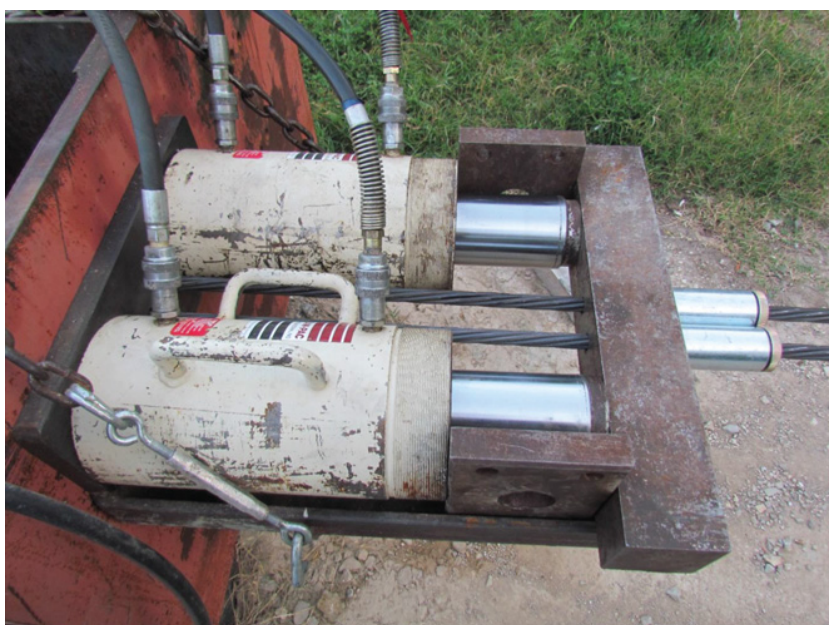

Figure 1. General view of the hydraulic system used in the research

\subsection{Determination of development length}

The determination of development length is an iterative procedure in which the beams are tested at different embedment lengths (Dang et al., 2016a). A concentrated load was applied by an $890 \mathrm{kN}$ hydraulic actuator to the beam at a given distance (embedment length) from the beam end, and increased until the beam failed. The bending tests are expected to show a clear progression in which the beams show flexural failures with long embedment lengths and shear/bond or bond failures with short embedment lengths. Two bending tests were performed for each beam as shown in Figure 2. For the first test span, AC, cracks occurred in the testing region and adjacent to the loading position (point $\mathrm{M}$ ), and there were no cracks adjacent to point B. Therefore, the first bending test had no effect on the second test. On the second test span, BD, the testing region was shorter than the remaining region, $\mathrm{BN}$, which was responsible for possible strand slip in the testing region and no strand slip in the region $\mathrm{BN}$.

During a bending test, a data acquisition system was used to monitor the concentrated load, strand slip and beam deflection. During a bending test, the prestressing strands may slip due to an excessive bond stress in the transfer and flexuralbond zone. The strand slip was measured using two linear variable differential transformers attached to the strands.

If the bending test shows a flexural failure (Figure 3), the tested embedment length is equal to or greater than the required development length. A flexural failure is specified by two requirements: $(i)$ the maximum moment $\left(M_{\max }\right)$ is equal to or greater than the nominal flexural resistance $\left(M_{\mathrm{n}}\right)$, and (ii) the prestressing strands do not slip prior to the beam achieving $M_{\mathrm{n}}$. Thirtytwo out of 50 bending tests exhibited flexural failures. These beams showed similar crack patterns. When the beam reached the cracking moment, a major crack occurred at the loading position and propagated towards the concentrated load. There were several minor cracks in the flexural-bond zone, and the beam had no sign of cracking in the transfer zone.

A shear/bond failure (Figure 4) exhibits visible shear cracks in the transfer zone. The shear cracks occurred near the support,

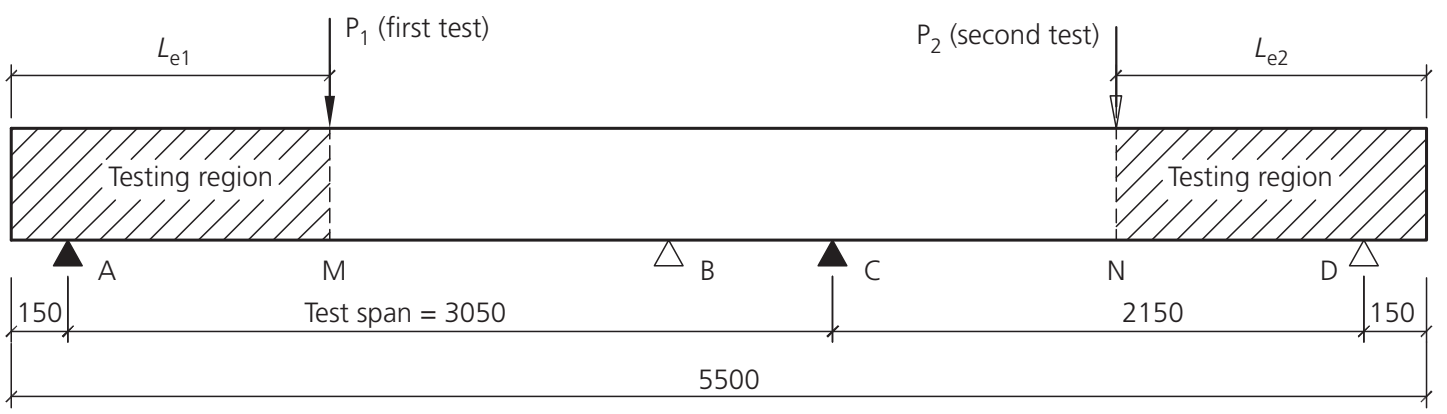

Figure 2. Bending test of a pretensioned concrete beam 


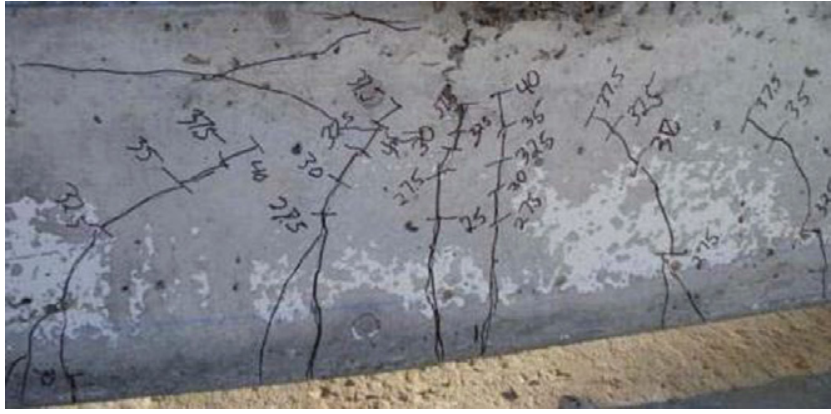

Figure 3. A typical flexural failure (specimen NSC-2L)

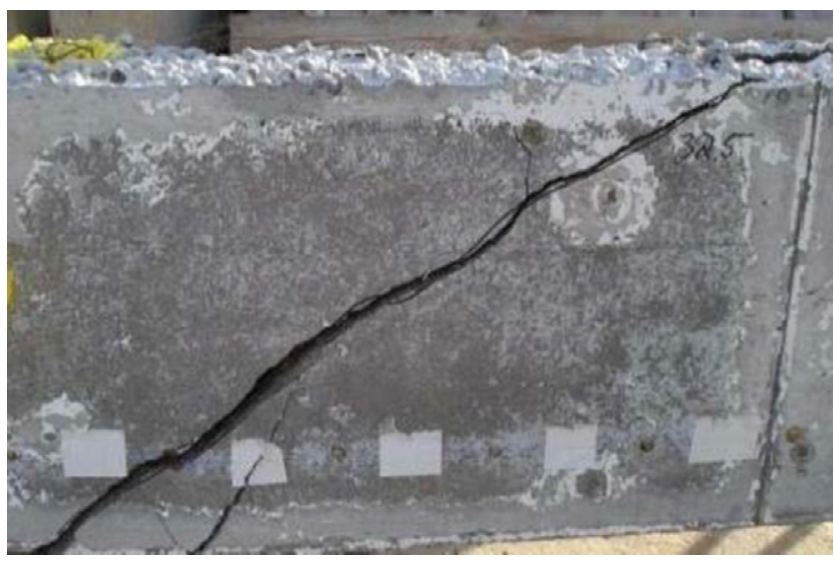

Figure 4. A typical shear/bond failure (specimen NSC-3D)

inclined at $30-45^{\circ}$ from the horizontal line, and propagated towards the concentrated load. The beam possibly fails suddenly, and the prestressing strands experience significant slip when the cracks occur. The beam behaviour is acceptable if $M_{\mathrm{n}}$ is achieved at failure. For this case, the tested embedment length is equal to or greater than the required development length. If the beam fails prior to achieving $M_{\mathrm{n}}$, the tested embedment length is possibly shorter than the required development length. Fourteen out of 50 bending tests exhibited shear/bond failures.

The beam shows a bond failure (Figure 5) when the prestressing strands do not have an adequate flexural-bond length to develop the strand stress $f_{\mathrm{ps}}$. This beam does not achieve $M_{\mathrm{n}}$ at failure, and the prestressing strands experience significant slip. Four out of 50 bending tests exhibited bond failures. The crack pattern of the bond failure was different from those of the flexural failure and shear/bond failure. Several cracks occurred near the end of the transfer zone and propagated towards the concentrated load. The occurrence of these cracks increased the tensile stress in the prestressing strands (Figure 6), as the tensile stress in the prestressing strand in the transfer zone keeps increasing until failure due to the increase of the concentrated load, and decreased the bond strength

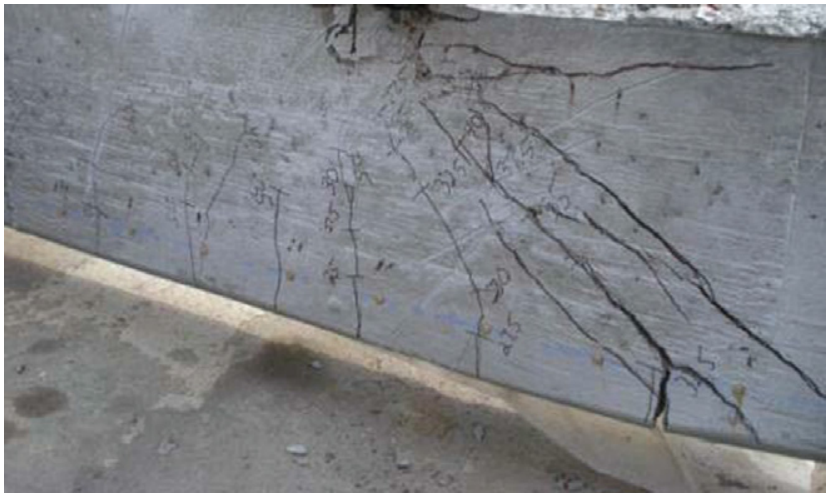

Figure 5. A typical bond failure (specimen HSS-4L)

generated by the Hoyer's effect because of the reduction in the strand diameter. When the beam reached $M_{\max }$, the strand slip continued to increase while the beam was unable to resist additional load.

\section{Experimental results and discussion}

The FESs and bending tests were measured at both ends of a pretensioned concrete beam. The test conducted at the dead end was designated as $D$, and at the live end was designated as $L$.

\subsection{FES}

The measured FESs were compared to the end-slip threshold (Equation 3) to examine their variability. Figure 7 shows the FESs at the live end and dead end of 25 pretensioned concrete beams. The FES of beam NSS-1L was excluded from the figure because of the unavailability of equipment at the time of measurement. As shown in Figure 7, beam NSL-4D exhibited an excessive FES. The possible reason was the unexpected leakage of water at one end plate of the wooden forms when the beams NSL-3 and NSL-4 were cast. Therefore, the concrete consolidation at the dead end of beam NSL-4 was not as good as expected, and caused the loss in bond strength. Therefore, poor concrete consolidation can result in an excessive FES at prestress transfer. The remaining measurements varied from 0.75 to $1.75 \mathrm{~mm}$, which was $20-80 \%$ of the end-slip threshold. Figure 7 also shows that the variability in the measured FESs of the NSC beam group is greater than the other groups. This variability was possibly due to the slight inconsistency of the NSC mixtures.

\subsection{Development length}

Tables 2 and 3 show the bending-test results of the 25 pretensioned concrete beams. For the NSC beam group, embedment lengths $\left(L_{\mathrm{e}}\right)$ varied from 1143 to $1524 \mathrm{~mm}$. Beam NSC-1D showed a flexural failure at $L_{\mathrm{e}}=1270 \mathrm{~mm}$. Beams NSC-2D, NSC-2L and NSC-4L also exhibited flexural failures at $L_{\mathrm{e}} \geq 1270 \mathrm{~mm}$. Beam NSC-3D experienced a shear/bond failure at $L_{\mathrm{e}}=1321 \mathrm{~mm}$; a visible shear crack occurred in the 

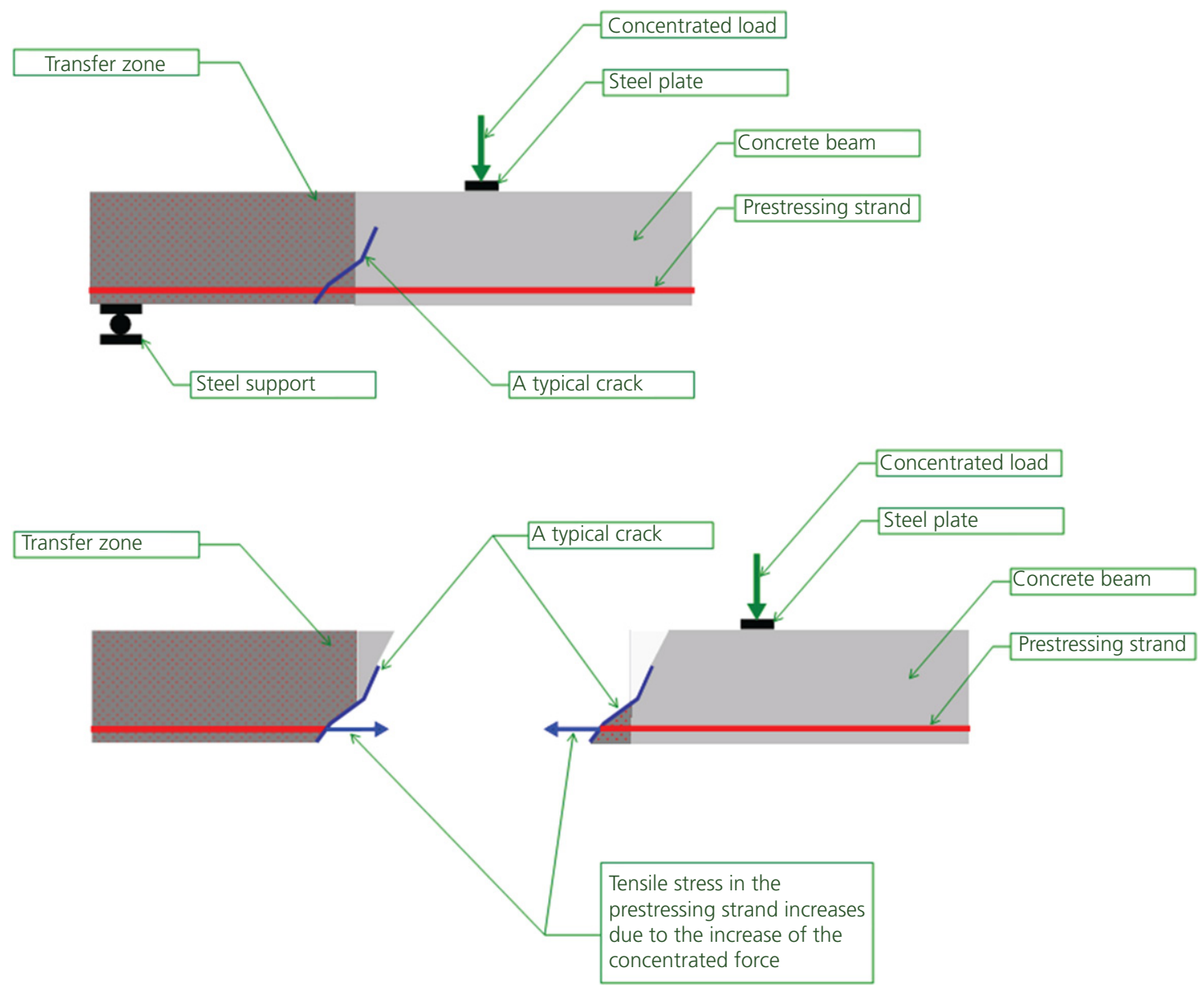

Figure 6. Increase in strand tensile stress due to cracks in the transfer zone

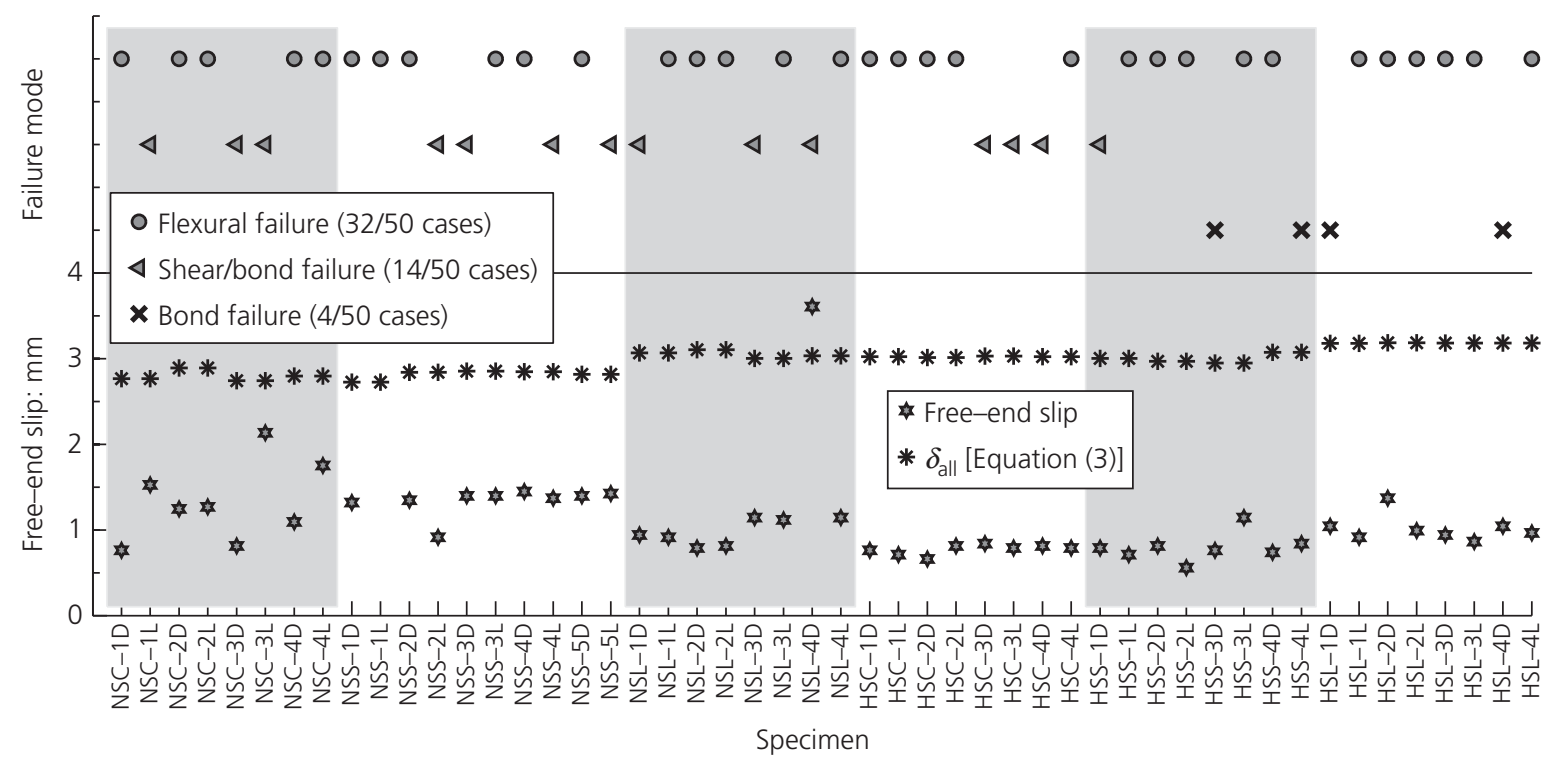

Figure 7. Measured FESs, end-slip threshold and mode of failures at the dead end and live end of 25 pretensioned concrete beams 
Table 2. Development length test results of the beams using NSC

\begin{tabular}{|c|c|c|c|c|c|c|c|c|c|}
\hline No. & Specimen & $f_{\mathrm{c}}^{\prime}: \mathrm{MPa}$ & $f_{\mathrm{pe}}: \mathrm{MPa}$ & $f_{\mathrm{ps}}: \mathrm{MPa}$ & $L_{\mathrm{e}}: \mathrm{mm}$ & $M_{\mathrm{n}}: \mathbf{k N} \times \mathbf{m}$ & $M_{\text {max }}: \mathbf{k N} \times \mathbf{m}$ & Deflection: $\mathrm{mm}$ & Failure type \\
\hline \multicolumn{10}{|c|}{ NSC beams } \\
\hline 1 & NSC-1D & $34 \cdot 7$ & $1056 \cdot 3$ & $1792 \cdot 0$ & 1270 & $106 \cdot 2$ & $106 \cdot 9$ & 48 & $\mathrm{FL}$ \\
\hline 2 & NSC-1L & $34 \cdot 7$ & $1056 \cdot 3$ & $1792 \cdot 0$ & 1143 & $106 \cdot 2$ & $80 \cdot 0$ & 31 & $\mathrm{SH} / \mathrm{BD}$ \\
\hline 3 & NSC-2D & $46 \cdot 2$ & $1104 \cdot 6$ & $1808 \cdot 6$ & 1270 & 111.9 & $121 \cdot 4$ & 30 & $\mathrm{FL}$ \\
\hline 4 & NSC-2L & $46 \cdot 2$ & $1104 \cdot 6$ & $1808 \cdot 6$ & 1397 & 111.9 & $124 \cdot 5$ & 54 & $\mathrm{FL}$ \\
\hline 5 & NSC-3D & $36 \cdot 0$ & $1048 \cdot 0$ & $1788 \cdot 6$ & 1321 & $106 \cdot 4$ & $110 \cdot 3$ & 25 & $\mathrm{SH} / \mathrm{BD}$ \\
\hline 6 & NSC-3L & $36 \cdot 0$ & $1048 \cdot 0$ & $1788 \cdot 6$ & 1219 & $106 \cdot 4$ & $96 \cdot 7$ & 18 & $\mathrm{SH} / \mathrm{BD}$ \\
\hline 7 & NSC-4D & $40 \cdot 0$ & $1068 \cdot 0$ & $1801 \cdot 7$ & 1219 & $109 \cdot 2$ & $117 \cdot 1$ & 30 & $\mathrm{FL}$ \\
\hline 8 & NSC-4L & $40 \cdot 0$ & $1068 \cdot 0$ & $1801 \cdot 7$ & 1524 & $109 \cdot 2$ & $124 \cdot 4$ & 55 & $\mathrm{FL}$ \\
\hline \multicolumn{10}{|c|}{ NSS beams } \\
\hline 9 & NSS-1D & $34 \cdot 4$ & $1041 \cdot 1$ & 1789.9 & 1143 & $105 \cdot 9$ & $115 \cdot 8$ & 70 & $\mathrm{FL}$ \\
\hline 10 & NSS-1L & $34 \cdot 4$ & $1041 \cdot 1$ & $1789 \cdot 9$ & 1270 & $105 \cdot 9$ & $114 \cdot 7$ & 55 & $\mathrm{FL}$ \\
\hline 11 & NSS-2D & $42 \cdot 1$ & $1084 \cdot 6$ & $1804 \cdot 4$ & 1245 & $110 \cdot 2$ & $112 \cdot 5$ & 22 & $\mathrm{FL}$ \\
\hline 12 & NSS-2L & $42 \cdot 1$ & $1084 \cdot 6$ & $1804 \cdot 4$ & 1016 & $110 \cdot 2$ & $109 \cdot 2$ & 21 & $\mathrm{SH} / \mathrm{BD}$ \\
\hline 13 & NSS-3D & $43 \cdot 0$ & $1089 \cdot 4$ & $1803 \cdot 7$ & 1016 & $109 \cdot 6$ & 94.5 & 19 & $\mathrm{SH} / \mathrm{BD}$ \\
\hline 14 & NSS-3L & $43 \cdot 0$ & $1089 \cdot 4$ & $1803 \cdot 7$ & 1143 & $109 \cdot 6$ & $117 \cdot 0$ & 58 & $\mathrm{FL}$ \\
\hline 15 & NSS-4D & $46 \cdot 2$ & $1087 \cdot 3$ & $1805 \cdot 8$ & 1219 & $110 \cdot 6$ & $113 \cdot 9$ & 61 & $\mathrm{FL}$ \\
\hline 16 & NSS-4L & $46 \cdot 2$ & $1087 \cdot 3$ & $1805 \cdot 8$ & 1143 & $110 \cdot 6$ & $114 \cdot 6$ & 19 & $\mathrm{SH} / \mathrm{BD}$ \\
\hline 17 & NSS-5D & $45 \cdot 1$ & $1076 \cdot 3$ & $1804 \cdot 4$ & 1143 & $110 \cdot 3$ & $117 \cdot 2$ & 80 & $\mathrm{FL}$ \\
\hline 18 & NSS-5L & $45 \cdot 1$ & $1076 \cdot 3$ & $1804 \cdot 4$ & 1016 & $110 \cdot 3$ & $94 \cdot 3$ & 15 & $\mathrm{SH} / \mathrm{BD}$ \\
\hline \multicolumn{10}{|c|}{ NSL beams } \\
\hline 19 & NSL-1D & $46 \cdot 3$ & $1171 \cdot 5$ & $1807 \cdot 9$ & 940 & $110 \cdot 5$ & $107 \cdot 7$ & 23 & $\mathrm{SH}$ \\
\hline 20 & NSL-1L & $46 \cdot 3$ & 1171.5 & $1807 \cdot 9$ & 1016 & $110 \cdot 5$ & $122 \cdot 1$ & 59 & $\mathrm{FL}$ \\
\hline 21 & NSL-2D & $55 \cdot 0$ & $1185 \cdot 3$ & $1812 \cdot 7$ & 1016 & $113 \cdot 1$ & 133.6 & 55 & $\mathrm{FL}$ \\
\hline 22 & NSL-2L & $55 \cdot 0$ & $1185 \cdot 3$ & $1812 \cdot 7$ & 1092 & $113 \cdot 1$ & 127.9 & 66 & $\mathrm{FL}$ \\
\hline 23 & NSL-3D & $54 \cdot 1$ & $1147 \cdot 3$ & $1811 \cdot 3$ & 1016 & $113 \cdot 1$ & $124 \cdot 3$ & 32 & $\mathrm{SH} / \mathrm{BD}$ \\
\hline 24 & NSL-3L & $54 \cdot 1$ & $1147 \cdot 3$ & $1811 \cdot 3$ & 864 & $113 \cdot 1$ & $116 \cdot 3$ & 36 & $\mathrm{FL}$ \\
\hline 25 & NSL-4D & $54 \cdot 2$ & $1159 \cdot 0$ & 1813.4 & 1422 & 113.6 & 93.7 & 26 & $\mathrm{SH} / \mathrm{BD}$ \\
\hline 26 & NSL-4L & $54 \cdot 2$ & $1159 \cdot 0$ & $1813 \cdot 4$ & 1194 & $113 \cdot 6$ & $130 \cdot 1$ & 34 & $\mathrm{FL}$ \\
\hline
\end{tabular}

$\mathrm{BD}$, bond failure; FL, flexural failure; $\mathrm{SH} / \mathrm{BD}$, shear/bond failure

transfer zone, and the prestressing strands slipped instantly when the beam achieved $M_{\mathrm{n}}$. Therefore, the required development length was less than $1270 \mathrm{~mm}$. Beams NSC-3L and NSC-4D showed different results at $L_{\mathrm{e}}=1219 \mathrm{~mm}$. Beam NSC-3L experienced a shear/bond failure and failed at $91 \%$ of $M_{\mathrm{n}}$; the formation of several shear cracks in the transfer zone caused the loss in the transfer-bond strength, and the beam was unable to resist additional load. Beam NSC-4D experienced a flexural failure with a number of cracks in the flexural bond zone. The difference in transfer lengths (greater for the case of NSC-3L) was a possible reason for this deviation. Beam NSC-1L failed at $75 \%$ of $M_{\mathrm{n}}$ with several shear cracks that were similar to those of beam NSC-3L. Therefore, the required development length was greater than $1143 \mathrm{~mm}$. In summary, the required development length of the NSC beam group was in the range of $1143-1270 \mathrm{~mm}$.

The bending test results of the NSS beam group showed two separate trends: flexural failures at $L_{\mathrm{e}} \geq 1143 \mathrm{~mm}$ (beams NSS-1D, NSS-1L, NSS-2D, NSS-3L, NSS-4D and NSS-5D) and shear/bond failures at $L_{\mathrm{e}}=1016 \mathrm{~mm}$ (beams NSS-2L, NSS-3D and NSS-5L); the only exception was beam NSS-4L, which had $L_{\mathrm{e}}=1143 \mathrm{~mm}$ and experienced a shear/bond failure (instead of flexural failure) with a visible shear crack that was formed at the support and propagated towards the concentrated load, and failed suddenly at $104 \%$ of $M_{\mathrm{n}}$. The remaining beams that exhibited shear/bond failure failed at $85-99 \%$ of $M_{\mathrm{n}}$ with shear cracks similar to those of beam NSS-4L. The test results of these beams indicated that the required development length was greater than $1016 \mathrm{~mm}$. In summary, the required development length of the NSS beam group was in the range of $1016-1143 \mathrm{~mm}$.

For the NSL beam group, the required development length was anticipated to be shorter than that of the NSC and NSS beam groups, since the bond of the prestressing strands with normal-weight concrete is possibly greater than with lightweight concrete. Beam NSL-4D was tested at a long embedment length of $1422 \mathrm{~mm}$ because the concrete consolidation was not good, as aforementioned. As expected, this beam failed at $82 \%$ of $M_{\mathrm{n}}$ with a visible shear crack occurring in the transfer zone, and the prestressing strands slipped instantly when the crack occurred. Beams NSL-4L and NSL-2L showed flexural failures when tested at $L_{\mathrm{e}}=1194 \mathrm{~mm}$ and $L_{\mathrm{e}}=1092 \mathrm{~mm}$, respectively. The remaining beams were tested at $L_{\mathrm{e}}$ varying from 940 to $1016 \mathrm{~mm}$. At $L_{\mathrm{e}}=1016 \mathrm{~mm}$, beams NSL-1L and NSL-2D experienced flexural failures with a number of cracks in the flexural-bond zone. Beam NSL-3D 
Table 3. Development length test results of the beams using HSC

\begin{tabular}{|c|c|c|c|c|c|c|c|c|c|}
\hline No. & Specimen & $f_{\mathrm{c}}^{\prime}: \mathrm{MPa}$ & $f_{\mathrm{pe}}: \mathrm{MPa}$ & $f_{\mathrm{ps}}: \mathrm{MPa}$ & $L_{\mathrm{e}}: \mathrm{mm}$ & $M_{\mathrm{n}}: \mathrm{kN} \times \mathbf{m}$ & $M_{\text {max }}: \mathrm{kN} \times \mathbf{m}$ & Deflection: $\mathbf{m m}$ & Failure type \\
\hline \multicolumn{10}{|c|}{ HSC beams } \\
\hline 27 & HSC-1D & $49 \cdot 4$ & $1154 \cdot 2$ & $1810 \cdot 6$ & 1016 & 111.9 & $114 \cdot 7$ & 26 & $\mathrm{FL}$ \\
\hline 28 & HSC-1L & $49 \cdot 4$ & $1154 \cdot 2$ & $1810 \cdot 6$ & 1270 & 111.9 & $125 \cdot 3$ & 51 & $\mathrm{FL}$ \\
\hline 29 & HSC-2D & $52 \cdot 0$ & $1150 \cdot 1$ & $1812 \cdot 0$ & 1118 & $112 \cdot 5$ & $116 \cdot 8$ & 67 & $\mathrm{FL}$ \\
\hline 30 & HSC-2L & $52 \cdot 0$ & $1150 \cdot 1$ & $1812 \cdot 0$ & 1143 & $112 \cdot 5$ & $116 \cdot 9$ & 48 & $\mathrm{FL}$ \\
\hline 31 & $\mathrm{HSC}-3 \mathrm{D}$ & $46 \cdot 3$ & $1157 \cdot 7$ & $1809 \cdot 9$ & 1092 & $110 \cdot 8$ & $104 \cdot 7$ & 22 & $\mathrm{SH} / \mathrm{BD}$ \\
\hline 32 & HSC-3L & $46 \cdot 3$ & $1157 \cdot 7$ & $1809 \cdot 9$ & 1143 & $110 \cdot 8$ & $118 \cdot 2$ & 26 & $\mathrm{SH} / \mathrm{BD}$ \\
\hline 33 & $\mathrm{HSC}-4 \mathrm{D}$ & $48 \cdot 8$ & $1154 \cdot 2$ & $1810 \cdot 6$ & 953 & 111.6 & $110 \cdot 6$ & 34 & $\mathrm{SH} / \mathrm{BD}$ \\
\hline 34 & HSC-4L & $48 \cdot 8$ & $1154 \cdot 2$ & $1810 \cdot 6$ & 1219 & $111 \cdot 6$ & $117 \cdot 8$ & 80 & $\mathrm{FL}$ \\
\hline \multicolumn{10}{|c|}{ HSS beams } \\
\hline 35 & HSS-1D & $45 \cdot 4$ & $1147 \cdot 3$ & $1808 \cdot 6$ & 1016 & $110 \cdot 6$ & $108 \cdot 3$ & 25 & $\mathrm{SH} / \mathrm{BD}$ \\
\hline 36 & HSS-1L & $45 \cdot 4$ & $1147 \cdot 3$ & $1808 \cdot 6$ & 1270 & $110 \cdot 6$ & $123 \cdot 0$ & 88 & $\mathrm{FL}$ \\
\hline 37 & HSS-2D & $44 \cdot 3$ & $1134 \cdot 2$ & $1807 \cdot 2$ & 1092 & $110 \cdot 2$ & $125 \cdot 0$ & 61 & $\mathrm{FL}$ \\
\hline 38 & HSS-2L & $44 \cdot 3$ & $1134 \cdot 2$ & $1807 \cdot 2$ & 1143 & $110 \cdot 2$ & $122 \cdot 1$ & 82 & $\mathrm{FL}$ \\
\hline 39 & HSS-3D & $55 \cdot 6$ & $1126 \cdot 0$ & $1812 \cdot 0$ & 889 & $113 \cdot 3$ & $105 \cdot 0$ & 49 & $\mathrm{BD}$ \\
\hline 40 & HSS-3L & $55 \cdot 6$ & $1126 \cdot 0$ & $1812 \cdot 0$ & 1016 & $113 \cdot 3$ & $108 \cdot 8$ & 62 & $\mathrm{FL}$ \\
\hline 41 & HSS-4D & $48 \cdot 3$ & $1173 \cdot 5$ & $1811 \cdot 3$ & 1016 & $111 \cdot 5$ & 118.8 & 94 & $\mathrm{FL}$ \\
\hline 42 & HSS-4L & $48 \cdot 3$ & $1173 \cdot 5$ & $1811 \cdot 3$ & 953 & $111 \cdot 5$ & $106 \cdot 7$ & 45 & $\mathrm{BD}$ \\
\hline \multicolumn{10}{|c|}{ HSL beams } \\
\hline 43 & HSL-1D & $61 \cdot 0$ & $1213 \cdot 5$ & $1818 \cdot 9$ & 1016 & 114.9 & $123 \cdot 6$ & 92 & $\mathrm{BD}$ \\
\hline 44 & HSL-1L & $61 \cdot 0$ & $1213 \cdot 5$ & $1818 \cdot 9$ & 1270 & 114.9 & $131 \cdot 7$ & 82 & $\mathrm{FL}$ \\
\hline 45 & HSL-2D & $63 \cdot 1$ & $1216 \cdot 3$ & $1820 \cdot 3$ & 1219 & $115 \cdot 5$ & $120 \cdot 2$ & 94 & $\mathrm{FL}$ \\
\hline 46 & HSL-2L & $63 \cdot 1$ & $1216 \cdot 3$ & $1820 \cdot 3$ & 1143 & $115 \cdot 5$ & $129 \cdot 6$ & 100 & $\mathrm{FL}$ \\
\hline 47 & HSL-3D & $64 \cdot 1$ & $1215 \cdot 6$ & $1820 \cdot 3$ & 1080 & $115 \cdot 7$ & $118 \cdot 4$ & 65 & $\mathrm{FL}$ \\
\hline 48 & HSL-3L & $64 \cdot 1$ & $1215 \cdot 6$ & $1820 \cdot 3$ & 1219 & $115 \cdot 7$ & $119 \cdot 3$ & 75 & $\mathrm{FL}$ \\
\hline 49 & HSL-4D & $66 \cdot 9$ & 1214.9 & $1821 \cdot 7$ & 889 & $116 \cdot 4$ & $107 \cdot 3$ & 59 & $B D$ \\
\hline 50 & HSL-4L & $66 \cdot 9$ & $1214 \cdot 9$ & $1821 \cdot 7$ & 1016 & $116 \cdot 4$ & 119.6 & 30 & $\mathrm{FL}$ \\
\hline
\end{tabular}

$\mathrm{FL}$, flexural failure; $\mathrm{SH} / \mathrm{BD}$, shear/bond failure; $\mathrm{BD}$, bond failure

experienced a shear/bond failure with several minor cracks in the flexural-bond zone and one visible shear crack that occurred in the transfer zone and propagated towards the concentrated load; the shear crack occurred after the beam achieved $M_{\mathrm{n}}$, and the beam failed at $110 \%$ of $M_{\mathrm{n}}$. Therefore, the required development length was less than $1016 \mathrm{~mm}$. Beam NSL-1L exhibited a shear/bond failure when tested at $L_{\mathrm{e}}=940 \mathrm{~mm}$, and failed at $97 \%$ of $M_{\mathrm{n}}$ with several cracks similar to those of beam NSL-3D. Beam NSL-3L, however, showed a flexural failure at $L_{\mathrm{e}}=864 \mathrm{~mm}$; this beam failed at $103 \%$ of $M_{\mathrm{n}}$ with several cracks in the flexural-bond zone and one visible crack beneath the concentrated load, and the prestressing strands slipped instantly when the beam achieved $M_{\mathrm{n}}$. These results indicated that the required development length was close to the tested $L_{\mathrm{e}}=864 \mathrm{~mm}$. In summary, the required development length of the beam group NSL was in the range of $864-940 \mathrm{~mm}$.

The HSC beam group was tested at $L_{\mathrm{e}}$ varying from 965 to $1270 \mathrm{~mm}$. Beams HSC-1L and HSC-4L showed flexural failures with several cracks in the flexural-bond zone when tested at $L_{\mathrm{e}}=1270 \mathrm{~mm}$ and $L_{\mathrm{e}}=1219 \mathrm{~mm}$, respectively. Beam HSC-2L experienced a flexural failure when tested at $L_{\mathrm{e}}=1118 \mathrm{~mm}$. Beam HSC-3L, however, experienced a shear/bond failure when tested at the same $L_{\mathrm{e}}$; this beam failed at $107 \%$ of $M_{\mathrm{n}}$ with a visible shear crack in the transfer zone, and the prestressing strands slipped instantly when the crack occurred. The difference in the behaviour of beams HSC-2L and HSC-3L was attributed to the formation of the cracks. For beam HSC-2L, there was no sign of cracking in the transfer zone, so the prestressing strands were adequately anchored in this zone to develop the design strength $f_{\mathrm{ps}}$. For beam HSC-3L, the first crack formed near the end of the transfer zone, which led to the increase in strand stress to a level greater than $f_{\mathrm{pe}}$ and caused excessive bond stress. The prestressing strands slipped when the bond stress exceeded the bond strength, which caused the loss in the shear strength contributed by the prestress and led to a shear/bond failure. Beam HSC-3D experienced a shear/bond failure at $95 \%$ of $M_{\mathrm{n}}$ with a number of cracks in the transfer and flexural-bond zone when tested at $L_{\mathrm{e}}=1092 \mathrm{~mm}$. Beam HSC-1D showed a flexural failure with a number of cracks in the flexural-bond zone, and the prestressing strands slipped when the beam achieved $102 \%$ of $M_{\mathrm{n}}$. These results indicated that the required development length was close to or slightly less than the tested $L_{\mathrm{e}}=1016 \mathrm{~mm}$. Beam HSC-4D failed at $99 \%$ of $M_{\mathrm{n}}$ when tested at $L_{\mathrm{e}}=965 \mathrm{~mm}$, with several cracks in the transfer zone, and the prestressing strands slipped instantly when the cracks occurred. Therefore, the required development length was greater than $965 \mathrm{~mm}$. In summary, the required development length of the beam group HSC was in the range of $965-1016 \mathrm{~mm}$. 
For the HSS beam group, the bending tests were performed at $L_{\mathrm{e}}$ varying from 889 to $1270 \mathrm{~mm}$. Beams HSS-1L, HSS-2D and HSS-2L experienced flexural failures with several cracks in the flexural-bond zone, and had no sign of cracking in the transfer zone when tested at $L_{\mathrm{e}} \geq 1092 \mathrm{~mm}$. Three beams were tested at an identical $L_{\mathrm{e}}=1016 \mathrm{~mm}$. Beam HSS-3L experienced a flexural failure with no sign of strand slip, but it failed at $96 \%$ of $M_{\mathrm{n}}$ since the concrete beneath the concentrated load was crushed; the difference between the measured concrete's compressive strength in the cylinders from the concrete strength in the beam was a possible reason for a flexural failure at $96 \%$ of $M_{\mathrm{n}}$. Beam HSS-1D showed a shear/bond failure with a visible shear crack that occurred at the support and propagated towards the concentrated load; this beam almost reached $M_{\mathrm{n}}$ at failure $\left(M_{\max }=98 \% \quad M_{\mathrm{n}}\right)$. Beam HSS-4D, however, exhibited a flexural failure at $106 \%$ of $M_{\mathrm{n}}$ with several cracks similar to those of beam HSS-2D. The test results of these beams indicated that the required development length was close to the tested $L_{\mathrm{e}}=1016 \mathrm{~mm}$. Beam HSS-4L showed a bond failure when tested at $L_{\mathrm{e}}=953 \mathrm{~mm}$; this beam failed at $96 \%$ of $M_{\mathrm{n}}$ with several cracks at the end of the transfer zone and significant strand slip. The remaining beam, HSS-3D, also experienced a bond failure similar to beam HSS-4L when tested at $L_{\mathrm{e}}=889 \mathrm{~mm}$. The bond failures of these beams indicated that the required development length was greater than $953 \mathrm{~mm}$. In summary, the required development length of the HSS beam group was in the range of 953-1016 mm.

The bending tests of the HSL beam group were conducted at $L_{\mathrm{e}}$ varying from 889 to $1270 \mathrm{~mm}$. Beams HSL-1L, HSL-2D, HSL-2L, HSL-3D and HSL-3L experienced flexural failures with a visible crack that occurred at the loading position and propagated towards the concentrated load when tested at $L_{\mathrm{e}} \geq 1080 \mathrm{~mm}$. Therefore, the required development length was less than $1080 \mathrm{~mm}$. Two beams were tested at $L_{\mathrm{e}}=1016 \mathrm{~mm}$ : beam HSL-4L showed a flexural failure when tested at $L_{\mathrm{e}}=1016 \mathrm{~mm}$, whereas beam HSL-1D experienced a bond failure (a visible crack occurred at the end of the transfer zone and propagated towards the concentrated load, which caused the strand slip prior to the beam achieving $M_{\mathrm{n}}$ ). Beam HSL4D also showed a bond failure, and the beam failed at $90 \%$ of $M_{\mathrm{n}}$ when tested at $L_{\mathrm{e}}=889 \mathrm{~mm}$. Therefore, the required development length was greater than $1016 \mathrm{~mm}$. In summary, the required development length of the HSL beam group was in the range of 1016-1080 $\mathrm{mm}$.

Figure 8 summarises the measured development lengths of the six beam groups. For the beam groups using NSC, the beams using lightweight aggregates (NSC and NSS) had slightly greater development lengths when compared to the beams using normal-weight aggregate (NSL). This variation may be attributed to the difference in aggregate stiffness. The development length of the beams using high-strength concrete (HSC, HSS and HSL) was almost identical regardless of the types of aggregate. Regardless of the effect of concrete properties, the measured development lengths were approximately $50 \%$ of the predicted values using the ACI 318-14 equation (ACI, 2014).

\subsection{Development of a new technique to quantify development length}

Logan's criteria (1997) were validated for $13 \mathrm{~mm}$ diameter strands, which possibly limits the applications of the slip theory

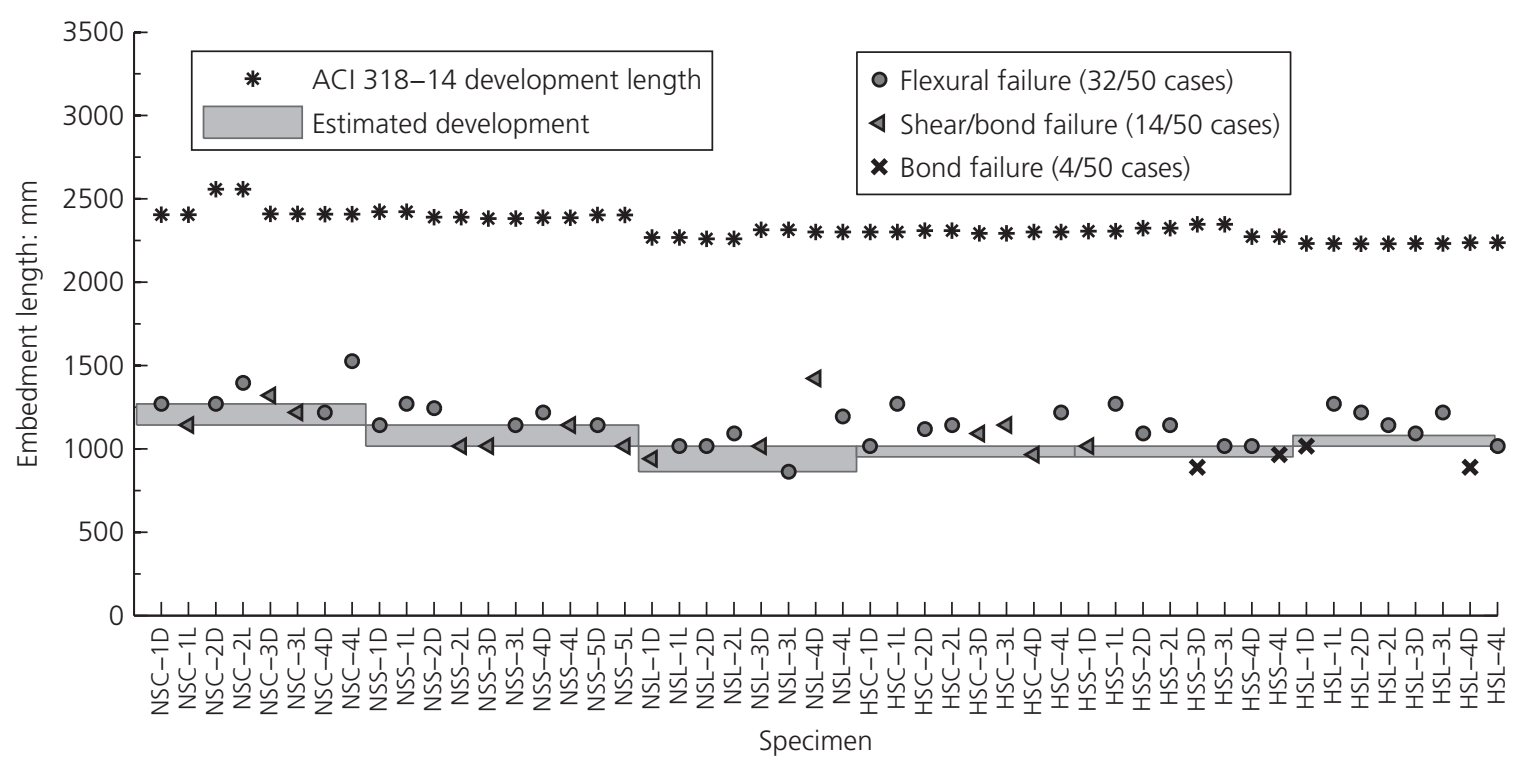

Figure 8. Measured development lengths, predicted development length and mode of failures at the dead end and live end of 25 pretensioned concrete beams 
in the current practice when increased diameter strands are used. Therefore, the authors propose using the end-slip threshold (Equation 3), which includes the strand diameter as a variable, to establish a correlation with the development length. By defining a normalised FES as the ratio of the measured FES to the end-slip threshold, the revised-slip theory can be stated as following: for a pretensioned concrete member that has a normalised FES less than or equal to 1 , the actual development length in this member is less than or equal to the predicted development length using the ACI 318-14 equation (ACI, 2014).

Figure 9 shows the relationship of the normalised FES and the normalised development length, which is the ratio of the required development length to the predicted development length using Equation 1. As shown in the figure, the experimental results of this study show a good agreement with the revisedslip theory. It should be mentioned that the data of beam NSS-1L were excluded because of the unavailability of the measured FES. The data of beam NSL-4D can be disregarded since this beam exhibited an unexpected poor consolidation and did not represent the general behaviour of the NSL beam group. In summary, the revised-slip theory provides a simple technique to predict the development length using the measured FES at prestress transfer.

\subsection{Validation of the revised-slip theory}

The applicability of this theory can be affected by the size of pretensioned concrete members, concrete properties, strand properties and release techniques as discussed previously. This study confirmed the applicability for the laboratory-scale pretensioned concrete beams that used $15 \mathrm{~mm}$ diameter strands and the six SCC mixtures. For an additional validation, the researchers intentionally selected several studies in the literature that used various types of concrete, strand diameters, beam cross-sections and release techniques.
Shah et al. (1996) measured FESs and development lengths for four full-scale Texas Type C (I-shape) girders that were $1016 \mathrm{~mm}$ deep with a $178 \mathrm{~mm}$ web. Two girders were cast with NSC $\left(f_{\mathrm{c}}^{\prime}=49.7 \mathrm{MPa}\right)$. The remaining girders were cast with high-performance concrete (HPC, $f_{\mathrm{c}}^{\prime}=91.9 \mathrm{MPa}$ ). Each girder contained $2015 \mathrm{~mm}$ diameter strands that were tensioned to $1376 \mathrm{MPa}\left(0 \cdot 74 f_{\mathrm{pu}}\right)$ prior to casting the concrete and gradually detensioned $24 \mathrm{~h}$ after casting. The average FESs were $1.9 \mathrm{~mm}$ and $1.3 \mathrm{~mm}$ for NSC and HPC girders, respectively. To determine the required development length, four bending tests were conducted for each set of girders. The tested embedment lengths were $3050 \mathrm{~mm}, 2360 \mathrm{~mm}, 1980 \mathrm{~mm}$ and $1830 \mathrm{~mm}$. At the shortest embedment length of $1830 \mathrm{~mm}$, both HPC girders and NSC girders exhibited flexural failures. Therefore, the required development length of $15 \mathrm{~mm}$ diameter strands was expected to be shorter than $1830 \mathrm{~mm}$. For simplification, this embedment length was used to calculate the normalised development length. As shown in Figure 9, the revised-slip theory conservatively predicts the development length for both NSC and HPC girders.

Myers et al. (2012) measured the FESs and development lengths for pretensioned concrete beams that had an identical cross-section with the beams used in this study. However, these beams contained $13 \mathrm{~mm}$ diameter strands that were tensioned to $1396 \mathrm{MPa}\left(0 \cdot 75 f_{\mathrm{pu}}\right)$ and detensioned abruptly using bolt cutters 24-26 h after casting concrete. Four concrete mixtures were used to cast the beams. These mixtures were identified as C6 (conventional concrete, $f_{\mathrm{c}}^{\prime}=39 \cdot 5 \mathrm{MPa}$ ), $\mathrm{C} 10$ (conventional concrete, $\left.f_{\mathrm{c}}^{\prime}=58.5 \mathrm{MPa}\right), \mathrm{S} 6\left(\mathrm{SCC}, f_{\mathrm{c}}^{\prime}=48.0 \mathrm{MPa}\right)$ and $\mathrm{S} 10$ $\left(\mathrm{SCC}, f_{\mathrm{c}}^{\prime}=63.8 \mathrm{MPa}\right)$. The average FESs were $1.6 \mathrm{~mm}$, $1.4 \mathrm{~mm}, 1.3 \mathrm{~mm}$ and $1.5 \mathrm{~mm}$ for the beams C6, C10, S6 and S10, respectively. The development length of the prestressing strands was determined by conducting bending tests at the embedment lengths of $80 \%$ and $100 \%$ of the development

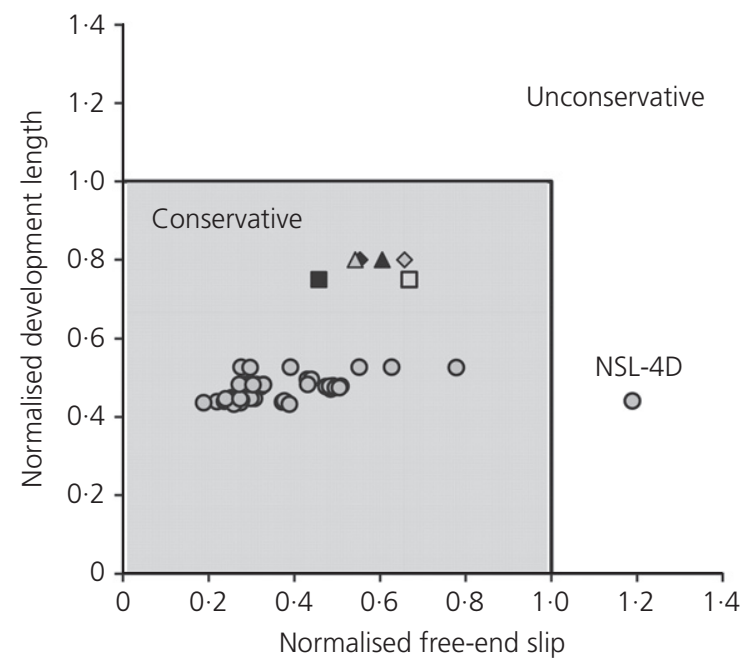

o Experimental data (49 points)

口Shah et al. (1996), NSC girders

- Shah et al. (1996), HPC girders

$\diamond$ Myers et al. (2012), C6 beams

- Myers et al. (2012), S6 beams

$\Delta$ Myers et al. (2012), C10 beams

$\Delta$ Myers et al. (2012), S10 beams 
length predicted using the ACI 318-14 equation (ACI, 2014). All of the bending tests that were tested at $80 \%$ of the predicted development length showed flexural failures. Therefore, the required development length of $13 \mathrm{~mm}$ diameter strands was expected to be shorter than $80 \%$ of the predicted value. The results shown in Figure 9 use a ratio of 0.8 as the normalised development length. This figure indicates that the revisedslip theory is applicable to predict the development length of the prestressing strands.

\section{Conclusions}

This study developed a simple and reliable technique to predict the development length of prestressing strands based on the measured FES at prestress transfer. Based on the investigations, the following conclusions were made:

- The measured FESs vary from $20 \%$ to $80 \%$ of the proposed end-slip threshold. Poor concrete consolidation can cause an excessive FES.

- For normal-strength SCC, the measured development length of the beams using normal-weight concrete is slightly less than that of the beams using lightweight concrete. The use of lightweight aggregates possibly results in lower bond strength when compared to normal-weight aggregate.

- For high-strength SCC, the measured development lengths of the beams using normal-weight and lightweight concrete are almost identical. The use of lightweight aggregates has minimal effect on the bond strength when compared to normal-weight aggregate.

- The measured development lengths range from 864 to $1270 \mathrm{~mm}$. The ACI 318-14 equation overestimates the measured development length of $15 \mathrm{~mm}$ diameter strands up to $100 \%$.

- The slip theory has been revised to develop a simple and reliable technique to predict the development length using the measured FES at prestress transfer. The application of the revised-slip theory has been validated on pretensioned concrete members that use concrete, prestressing strands, cross-sections and release techniques similar to those presented in this study, Shah et al. (1996) and Myers et al. (2012).

- The revised-slip theory can be adopted as a quality-control test to examine the adequacy of the ACI 318-14 (ACI, 2014) development-length equation when new materials or design parameters are introduced for pretensioned concrete applications. The FES of prestressing strands is an indicator of the flexural resistance of pretensioned concrete members.

\section{Acknowledgements}

The authors would like to acknowledge the financial and technical support of the Arkansas State Highway and Transportation Department (AHTD), Mack-Blackwell Rural Transportation
Center (MBTC) and Ton Duc Thang University. The contents of this paper reflect the views of the authors, and do not necessarily reflect the views of the research sponsors.

\section{REFERENCES}

Abdelatif AO, Owen JS and Hussein MFM (2015) Modelling the prestress transfer in pre-tensioned concrete elements. Engineering Structures 94: 47-63.

ACI (American Concrete Institute) (2014) ACI 318-14: Building code requirements for structural concrete and commentary. American Concrete Institute, Farmington Hills, MI, USA.

Anderson AR and Anderson RG (1976) An assurance criterion for flexural bond pretensioned hollow core units. ACI Journal 73(8): $457-464$

ASTM (2012) A1081: Standard test method for evaluating bond of seven-wire steel prestressing strand. ASTM International, West Conshohocken, PA, USA.

ASTM (2014a) C1611: Standard test method for slump flow of self-consolidating concrete. ASTM International, West Conshohocken, PA, USA.

ASTM (2014b) C1621: Standard test method for passing ability of self-consolidating concrete by J-ring. ASTM International, West Conshohocken, PA, USA.

ASTM (2015) C127: Standard test method for relative density (specific gravity) and absorption of coarse aggregate. ASTM International, West Conshohocken, PA, USA.

Brooks MD, Gerstle KH and Logan DR (1988) Effect of initial strand slip on the strength of hollow-core slabs. PCI Journal 33(1): $90-111$.

Burgueño R and Haq M (2007) Effect of SCC mixture proportioning on transfer and development length of prestressing strand. ACI Special Publication 247: 105-116.

Bymaster JC, Dang CN, Floyd RW and Hale WM (2015) Prestress losses in pretensioned concrete beams cast with lightweight self-consolidating concrete. Structures 2: 50-57.

Dang CN (2015) Measurement of Transfer and Development Lengths of $0 \cdot 7$ in. Strands on Pretensioned Concrete Elements. $\mathrm{PhD}$ dissertation. University of Arkansas, Fayetteville, AK, USA

Dang CN, Murray CD, Floyd RW, Hale WM and Martí-Vargas JR (2014) A correlation of strand surface quality to transfer length. ACI Structural Journal 111(5): 1245-1252.

Dang CN, Floyd RW, Murray CD, Hale WM and Martí-Vargas JR (2015) Bond stress-slip model for 0.6 in. $(15 \cdot 2 \mathrm{~mm})$ diameter strand. ACI Structural Journal 112(5): 625-634.

Dang CN, Floyd RW, Hale WM and Martí-Vargas JR (2016a) Measured development lengths of 0.7 in. $(17.8 \mathrm{~mm})$ strands for pretensioned beams. ACI Structural Journal 113(3): 525-535.

Dang CN, Floyd RW, Hale WM and Martí-Vargas JR (2016b) Measured transfer lengths of $0 \cdot 7 \mathrm{in} .(17 \cdot 8 \mathrm{~mm})$ strands for pretensioned beams. ACI Structural Journal 113(1): 85-94.

Dang CN, Floyd RW, Hale WM and Martí-Vargas JR (2016c) Spacing requirements of $0.7 \mathrm{in} .(18 \mathrm{~mm})$ diameter prestressing strands. PCI Journal 61(1): 70-87.

Dang CN, Floyd RW, Prinz GS and Hale WM (2016d) Determination of bond stress distribution coefficient by maximum likelihood method. Journal of Structural Engineering 142(5): 1-10.

Elliott KS (2014) Transmission length and shear capacity in prestressed concrete hollow core slabs. Magazine of Concrete Research 66(12): 585-602, https://doi.org/10.1680/macr.13.00251.

Elliott KS and Marti-Vargas JR (2015) Discussion: transmission length and shear capacity in prestressed concrete hollow core slabs. Magazine of Concrete Research 67(14): 798-799, https://doi.org/ $10.1680 /$ macr.15.00088. 
Floyd RW, Hale WM and Howland MB (2015) Measured transfer length of 0.6 in. prestressing strands cast in lightweight self-consolidating concrete. PCI Journal 60(3): 84-98.

Guyon Y (1953) Pretensioned Concrete: Theoretical and Experimental Study. Eyrolles, Paris, France.

Hanson NW and Kaar PH (1959) Flexural bond tests of pretensioned prestressed beams. ACI Journal 55(7): 783-803.

Khayat K and Mitchell D (2009) Self-Consolidating Concrete for Precast, Prestressed Concrete Bridge Elements. Transportation Research Board, Washington, DC, USA, NCHRP-628.

Lees JM and Burgoyne CJ (1999) Transfer bond stresses generated between FRP tendons and concrete. Magazine of Concrete Research 51(4): 229-239, https://doi.org/10.1680/macr.1999.51.4.229.

Logan DR (1997) Acceptance criteria for bond quality of strand for pretensioned prestressed concrete applications. PCI Journal 42(2): 52-90.

Maguire M, Morcous G and Tadros M (2013) Structural performance of precast/prestressed bridge double-tee girders made of high-strength concrete, welded wire reinforcement, and 18-mm-diameter strands. Journal of Bridge Engineering 18(10): 1053-1061.

Martí-Vargas JR, Serna-Ros P, Fernández-Prada MA, Miguel-Sosa PF and Arbeláez CA (2006) Test method for determination of the transmission and anchorage lengths in prestressed reinforcement. Magazine of Concrete Research 58(1): 21-29, https://doi.org/ 10.1680/macr.2006.58.1.21

Martí-Vargas JR, Ferri FJ and Yepes V (2013a) Prediction of the transfer length of prestressing strands with neural networks. Computers and Concrete 12(2): 187-209.

Martí-Vargas JR, García-Taengua E and Serna P (2013b) Influence of concrete composition on anchorage bond behaviour of prestressing reinforcement. Construction and Building Materials 48: 1156-1164.

Martí-Vargas JR, Hale WM, García-Taengua E and Serna P (2014) Slip distribution model along the anchorage length of prestressing strands. Engineering Structures 59: 674-685.

Mayfield B, Davies M and Kong FK (1970) Some test on transmission length and ultimate strength of pre-tensioned concrete beams incorporating Dyform strand. Magazine of Concrete Research 22(73): 219-226, https://doi.org/10.1680/macr.1970.22.73.219.

Mitchell D, Cook WD, Khan AA and Tham T (1993) Influence of high strength concrete on transfer and development length of pretensioning strand. PCI Journal 38(3): 52-66.
Morcous G, Assad S, Hatami A and Tadros MK (2014) Implementation of $0.7 \mathrm{in}$. diameter strands at $2 \cdot 0 \times 2 \cdot 0 \mathrm{in}$. spacing in pretensioned bridge girders. PCI Journal 59(3): 145-158.

Myers JJ, Volz JS, Sells E et al. (2012) Self-Consolidating Concrete (SCC) for Infrastructure Elements: Bond, Transfer Length, and Development Length of Prestressing Strand in SCC. Missouri Department of Transportation, Missouri University of Science and Technology, Rolla, MI, USA, CMR 13-003 Report B.

Oh BH and Kim ES (2000) Realistic evaluation of transfer lengths in pretensioned, prestressed concrete members. ACI Structural Journal 97(6): 821-830.

Park H, Din ZU and Cho J (2012) Methodological aspects in measurement of strand transfer length in pretensioned concrete. ACI Structural Journal 109(5): 625-633.

Petrou MF, Wan B, Joiner WS, Trezos CG and Harries KA (2000) Excessive strand end slip in prestressed piles. ACI Structural Journal 97(5) 774-782.

Rose D and Russell B (1997) Investigation of standardized tests to measure the bond performance of prestressing strand. PCI Journal 42(4): 56-80.

Russell BW and Burns N (1997) Measurement of transfer lengths on pretensioned concrete elements. Journal of Structural Engineering 123(5): 541-549.

Russell BW and Burns NH (1993) Design Guidelines for Transfer Development and Debonding of Large Diameter Seven Wire Strands in Pretensioned Concrete Girders. Texas Department of Transportation, Austin, TX, USA, FHWA/TX-93+1210-5F

Shah AN, Burns NH, Carrasquillo R and Fowler DW (1996) Bond Behaviour of 0.6-inch Diameter Prestressing Strand at Two-inch Grid Spacing in Fully Bonded High Strength and Normal Strength Composite Texas Type C Beams. Center for Transportation, The University of Texas at Austin, Austin, TX, USA, 589-2.

Song W, Ma ZJ, Vadivelu J and Burdette EG (2013) Transfer length and splitting force calculation for pretensioned concrete girders with high-capacity strands. Journal of Bridge Engineering 19(7): $1-8$.

Tabatabai H and Dickson TJ (1993) The history of the prestressing strand development length equation. PCI Journal 38(6): 64-75.

Wan B, Harries KA and Petrou MF (2002) Transfer length of strands in prestressed concrete piles. ACI Structural Journal 99(5): $577-585$. 